Open Access

\title{
Preoperative palsy score has no significant association with survival in non-small-cell lung cancer patients with spinal metastases who undergo spinal surgery
}

\author{
Yen-Jen Chen ${ }^{1,2,3^{*}} \mathbb{D}$, Hsien-Te Chen ${ }^{1}$ and Horng-Chaung Hsu ${ }^{1,2}$
}

\begin{abstract}
Background: Survival is a key factor physicians consider when selecting a treatment modality for the treatment of spinal metastases. Various assessment systems can predict length of survival and facilitate selection of the most appropriate treatment. Spinal palsy is a prognostic parameter in the Tokuhashi scoring system but not in the Tomita scoring system. A limitation of these scoring systems is that studies of them have included different tumor types. The aim of this study was to evaluate the usefulness of preoperative neurological status as a prognostic factor in non-small-cell lung cancer patients with spinal metastases who underwent surgical treatment.

Methods: From November 2000 to March 2010, 50 patients with symptomatic metastatic spinal cord compression secondary to non-small-cell lung cancer underwent palliative surgery. Data collected included patient age and sex, tumor histology, date of surgery, death or last follow-up, preoperative and postoperative ambulatory status according to the Frankel grading system, body mass index (BMI), number of vertebra involved, number of other bone metastasis, visceral metastasis, and preoperative Karnofsky performance status. Log-rank test and multivariate Cox proportional hazard regressions were used to evaluate possible prognostic factors.
\end{abstract}

Results: The mean patient age was 61.6 years (range, 20-87 years), and 34 were male and 16 were female. The median postoperative survival time was 7.5 months. The median survival was 2.5 months (95\% confidence interval (Cl): 1.22-16.3 months) in the Frankel A + B group and 8.0 months (95 \% Cl: 5.52-9.89 months) in the Frankel $C+D$ group $(p=0.87$ ). Multivariate Cox proportional hazard regressions showed that preoperative performance status was significantly associated with survival. Preoperative palsy score had no statistically significant association with survival.

Conclusions: Preoperative palsy score had no statistically significant association with survival in non-small-cell lung cancer patients with spinal metastases who underwent spinal surgery in this study.

Keywords: Lung cancer, Neurological status, Prognostic score, Spinal metastasis, Survival rate

\footnotetext{
*Correspondence: yenjenc.tw@yahoo.com.tw

'Department of Orthopedic Surgery, China Medical University Hospital

Taichung, Taiwan, No. 2, Yuh-Der Road, Taichung 404, Taiwan

${ }^{2}$ Department of Orthopedic Surgery, School of Medicine, China Medical

University, Taichung, Taiwan

Full list of author information is available at the end of the article
}

(c) 2015 Chen et al. Open Access This article is distributed under the terms of the Creative Commons Attribution 4.0 International License (http://creativecommons.org/licenses/by/4.0/), which permits unrestricted use, distribution, and reproduction in any medium, provided you give appropriate credit to the original author(s) and the source, provide a link to the Creative Commons license, and indicate if changes were made. The Creative Commons Public Domain Dedication waiver (http://creativecommons.org/publicdomain/zero/1.0/) applies to the data made available in this article, unless otherwise stated. 


\section{Background}

As advances in chemotherapy prolong the life expectancy of patients with solid tumors, the frequency of spinal metastases is likely to increase. Survival is a key factor physicians consider when selecting a treatment for spinal metastases. Various assessment systems can predict the length of survival and facilitate the selection of the most appropriate treatment. The assessment systems, however, differ with respect to the parameters assessed and the significance assigned to each parameter in the total score. Spinal palsy is one of the prognostic parameters in the Tokuhashi scoring system [1,2] but is not included in the Tomita scoring system [3]. A limitation of these scoring systems is that studies examining them have included different tumor types.

The aim of this study was to evaluate the usefulness of preoperative neurological status as a prognostic factor in non-small-cell lung cancer patients with spinal metastases who underwent surgical treatment.

\section{Material and methods Patients}

From November 2000 to March 2010, 50 patients with symptomatic metastatic spinal cord compression secondary to non-small-cell lung cancer underwent palliative surgery. A retrospective review of the hospital records and radiographs of these patients was conducted. The indication for surgery was neurologic deficit due to spinal cord compression. A single surgeon performed all the surgeries. The Research Ethics Committee (China Medical University \& Hospital, Taichung, Taiwan) approved this retrospective analysis (No. DMR101-IRB2-310).

All patients presented with weakness in the lower extremities, and 10 patients (20\%) remained ambulatory. The Frankel grading system [4] and a supplementary ambulatory status score were used during the preoperative and postoperative periods to evaluate neurologic status. Preoperative evaluations included plain radiographs and magnetic resonance imaging (MRI) or computed tomography (CT).

\section{Surgical interventions}

A total of 55 surgical procedures were performed on the 50 patients, and 46 patients underwent a single operation. Three patients underwent primary surgery for metastatic spinal cord compression, followed by a second operation for noncontiguous metastases. One patient underwent 3 additional procedures because of repeated local recurrences over a 3-year period.

Three patients underwent combined anterior and posterior procedures (anterior corpectomy, reconstruction with polymethylmethacrylate, and posterior instrumentation). Two patients with cervical spine metastases underwent anterior surgery. The remaining 45 (90 \%) patients underwent a posterolateral transpedicle approach (PTA). All patients underwent spinal instrumentation following adequate decompression. Local radiotherapy, systemic chemotherapy, and/or targeted therapy were performed after wound healing, usually 3-4 weeks after surgery.

\section{Factors for analysis}

Data collected included patient age and sex, tumor histology, date of surgery, death or last follow-up, preoperative and postoperative ambulatory status according to the Frankel grading system, body mass index (BMI), number of vertebra involved, number of other bone metastasis, visceral metastasis, and preoperative Karnofsky performance status. Overall survival was calculated from the date of surgery to the date of death.

Factors included in the analyses were sex, age $(\leq 54$, $55-74$, and $\geq 75$ years), tumor type (adenocarcinoma or nonadenocarcinoma), preoperative and postoperative palsy score (Frankel A + B vs. Frankel C + D vs. Frankel E), BMI (underweight vs. eutrophic vs. overweight/obese), number of vertebra involved ( $<3$ vs. $\geq 3$ ), other bone metastasis (without vs. with), visceral metastasis (without vs. with), and preoperative Karnofsky performance status (10-40\% vs. $50-70 \%$ vs. $80-100 \%)$.

\section{Statistical analysis}

Survival curves were plotted using the Kaplan-Meier method, and the significance of the differences between groups was determined using a log-rank test that considered the effects of age. The median survival time and $95 \%$ confidence interval $(\mathrm{CI})$ were then estimated based on the Brookmeyer and Crowley method [5]. A $p$ value $<0.05$ was considered statistically significant. Chi-squared test statistics and $p$ values were calculated based on the log-rank test of specific pairs. For variables with 2 subgroups, a $p<0.05$ was considered statistically significant. For variables with 3 subgroups, a $p<0.0167$ was considered statistically significant (the Bonferroni correction method was used to suppress a spurious significant difference).

Univariate and multivariate Cox proportional hazard regressions were used to detect possible prognostic factors. To investigate the most significant factors, factors

Table 1 Post-operative complications

\begin{tabular}{ll}
\hline Complication & Number of patients \\
\hline Neurologic progression & 1 \\
Wound dehiscence & 1 \\
Wound infection & 3 \\
Respiratory failure & 2 \\
CSF leakage & 2 \\
Sigmoid colon perforation & 1 \\
30-day mortality & 2 \\
\hline
\end{tabular}

CSF cerebrospinal fluid 


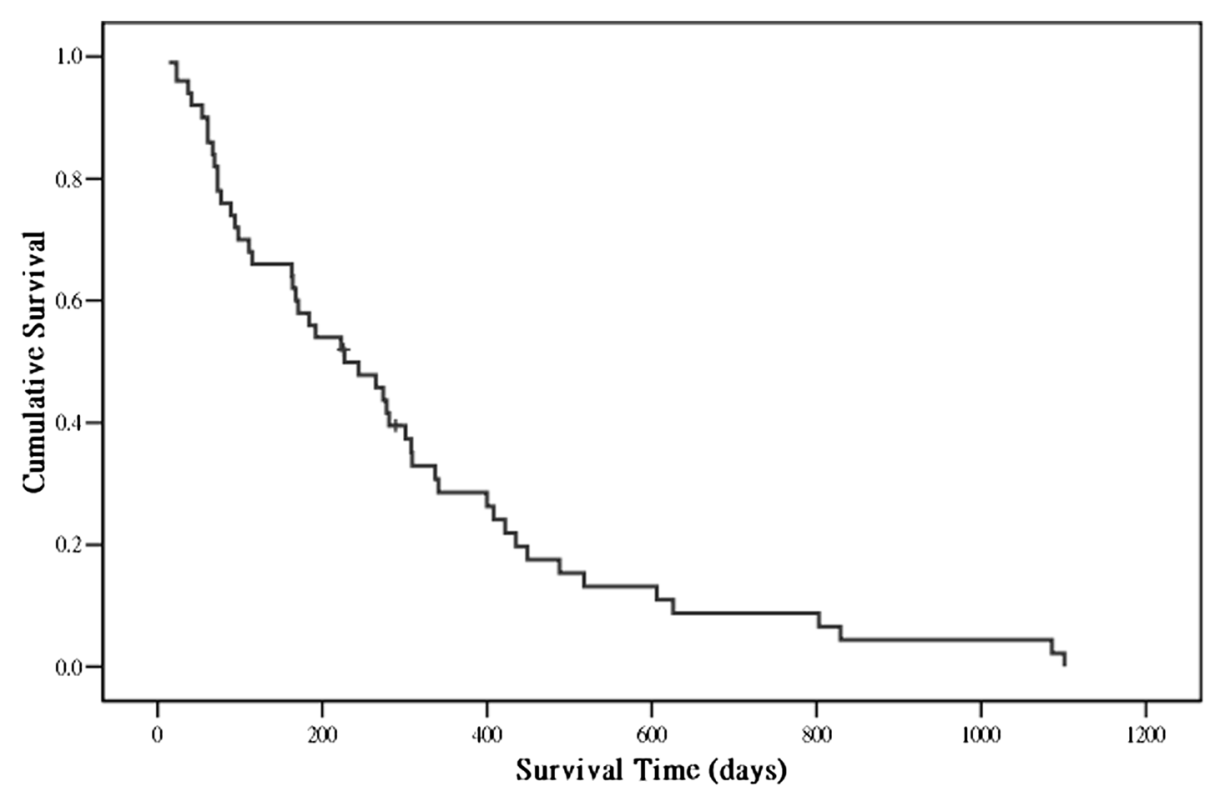

Fig. 1 Kaplan-Meier survival curve of the 50 lung cancer patients with spinal metastases who underwent spinal surgery

significantly impacted with survival in univariate analysis were included in multivariate analysis. Pre-op palsy score was considered to be the important factor, so it was included in multivariate analysis even no significance in univariate analysis. A $p<0.05$ was considered statistically significant. All analyses were performed using SAS 9.1 statistical software (SAS Institute, Inc, Cary, NC, USA).

\section{Results}

The mean patient age was 61.6 years (range, 20-87 years), and there were 34 males and 16 females. The tumor sites included the thoracic spine $(n=28)$, lumbar spine $(n=12)$, thoracolumbar spine $(n=6)$, cervical spine $(n=3)$, and sacrum $(n=1)$. Adenocarcinoma (32 patients) was the most common histological type, followed by squamous cell carcinoma (9 patients). The mean intraoperative blood loss volume was $975 \mathrm{~mL}$ (range, $350-6500 \mathrm{~mL}$ ), and the mean surgical time was $4.8 \mathrm{~h}$.

Neurologic improvement by $\geq 1$ Frankel grade was noted in 37 of the 50 cases $(74 \%)$. Twelve patients showed no improvement, and 1 patient showed deterioration from Frankel grade B to grade A. Overall, $68 \%$ of patients $(34 / 50)$ were ambulatory after surgery. Twenty-

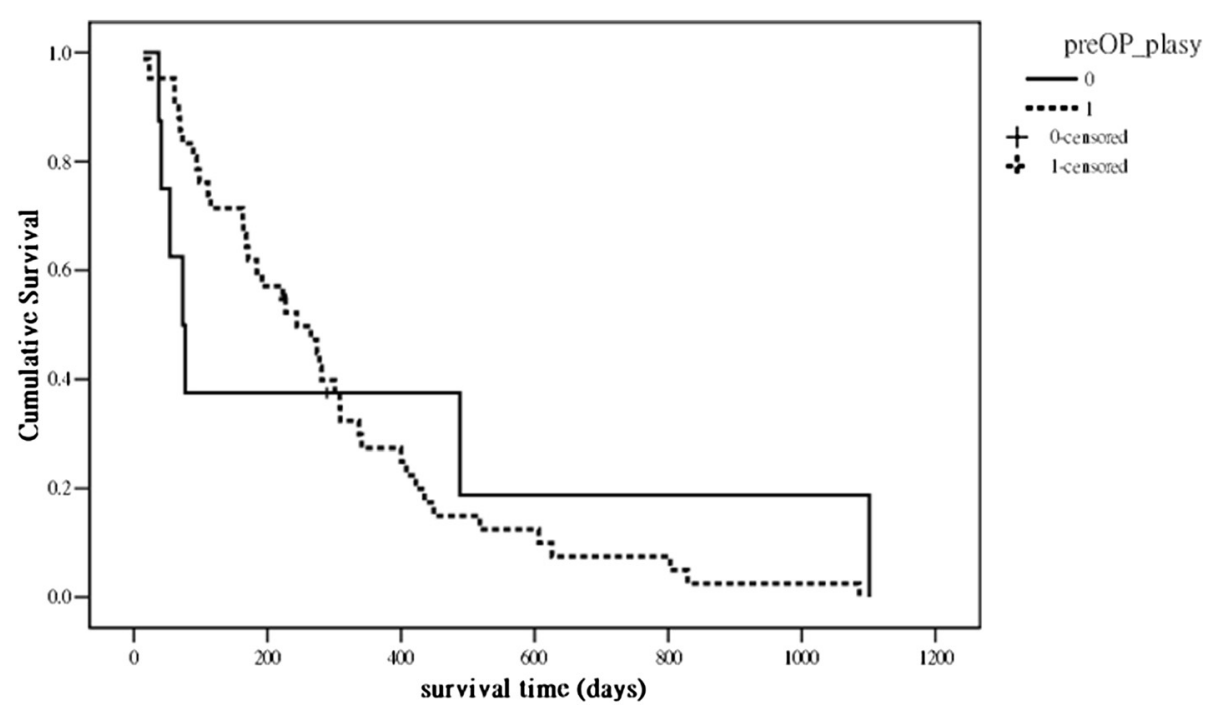

Fig. 2 Kaplan-Meier survival curve of the 50 patients with pre-operative Tokuhashi palsy score 0 vs score 1 ( $p=0.87$ ) 
two of $40(55 \%)$ nonambulatory (Frankel B/C) patients became ambulatory (Frankel D/E).

One patient developed symptomatic tumor recurrence at the level of previous decompression, and 3 patients developed new symptomatic spinal cord compressions

Table 2 Kaplan-Meier survival curve estimates for analysis of prognostic factors for survival

\begin{tabular}{|c|c|c|c|}
\hline \multirow[t]{2}{*}{ Variables } & \multirow[t]{2}{*}{$\begin{array}{l}\text { Number of } \\
\text { patients }\end{array}$} & $\begin{array}{l}\text { Median survival } \\
\text { (month) }\end{array}$ & \multirow[t]{2}{*}{$p$ value } \\
\hline & & $(95 \% \mathrm{Cl})$ & \\
\hline Age, year & & & $0.010^{*}$ \\
\hline$\leq 54$ & 16 & $9.5(3.22-11.07)$ & \\
\hline $55-74$ & 24 & $8.7(3.09-13.14)$ & \\
\hline$\geq 75$ & 10 & $3.7(2.0-5.52)$ & \\
\hline Sex & & & 0.220 \\
\hline M & 34 & $6.3(3.09-9.13)$ & \\
\hline $\mathrm{F}$ & 16 & $11.1(5.52-13.86)$ & \\
\hline Tumor histology & & & $0.003^{*}$ \\
\hline Adenocarcinoma & 32 & $9.9(7.43-11.20)$ & \\
\hline Non-adenocarcinoma & 18 & $3.5(2.20-5.39)$ & \\
\hline Pre-op palsy score & & & 0.870 \\
\hline 0 (Frankel 1,2) & 8 & $2.5(1.22-16.03)$ & \\
\hline 1 (Frankel 3, 4) & 42 & $8.0(5.52-9.89)$ & \\
\hline Post-op palsy score & & & $<0.001^{*}$ \\
\hline 0 (Frankel 1, 2) & 2 & $2.4(2.4-2.4)^{b}$ & \\
\hline 1 (Frankel 3, 4) & 32 & $5.5(2.92-7.33)$ & \\
\hline 2 (Frankel 5) & 16 & $14.3(9.23-17.02)$ & \\
\hline Pre-op PS & & & $<0.001^{*}$ \\
\hline Poor (0, PS 10-40\%) & 8 & $2.4(0.46-3.78)$ & \\
\hline Moderate (1, PS 50-70 \%) & 20 & $3.7(2.4-6.3)$ & \\
\hline Good (2, PS 80-100 \%) & 22 & $13.1(9.23-16.03)$ & \\
\hline BMI & & & 0.540 \\
\hline Underweight (1) & 5 & $6.3(0.59-12.02)$ & \\
\hline Eutrophic (2) & 31 & $6.0(3.18-8.91)$ & \\
\hline Overweight/obese (3) & 14 & $9.1(7.62-10.65)$ & \\
\hline Number of vertebra involved & & & 0.630 \\
\hline$<3$ & 24 & $6.3(3.15-9.46)$ & \\
\hline$\geq 3$ & 26 & $9.1(3.16-15.11)$ & \\
\hline Other bone metastasis & & & 0.818 \\
\hline Without & 20 & $5.4(1.25-9.46)$ & \\
\hline With & 30 & $8.7(6.56-10.85)$ & \\
\hline Visceral metastasis & & & 0.567 \\
\hline Without & 40 & $8.0(5.53-10.51)$ & \\
\hline With & 10 & $3.2(0-7.65)$ & \\
\hline
\end{tabular}

*Significant at $p$ value $<0.05$

${ }^{a} p$ value is calculated based on log-rank test over all stratification and takes

the effect of age into consideration

${ }^{\mathrm{b}}$ The $95 \% \mathrm{Cl}$ may be problematic due to too few data values

$P S$ performance status, $\mathrm{Cl}$ confidence interval, $\mathrm{BMI}$ body mass index because of noncontiguous metastases. These patients underwent repeat decompressive surgeries.

Of 12 observed complications (Table 1), 11 were surgery related. There was no intraoperative mortality; however, 3 patients died during the postoperative period. One patient died from respiratory failure 14 days after surgery, 1 died from hepatic and respiratory failure 23 days after surgery, and 1 died from nonsurgery-related sigmoid colon perforation and sepsis 37 days after surgery. The median postoperative survival time was 7.5 months $(95 \%$ CI: 4.210.9 months). The Kaplan-Meier curve (Fig. 1) showed that $58 \%(29 / 50)$ of the patients survived $>6$ months. The Frankel $\mathrm{A}+\mathrm{B}$ group (palsy score 0 in Tokuhashi system) contained 8 patients, and the Frankel $\mathrm{C}+\mathrm{D}$ group (palsy score 1 in Tokuhashi system) contained 42 patients. The median survival was 2.5 months (95 \% CI: 1.22-16.3 months) in the

Table 3 Pairwise comparisons of survival between subgroups

\begin{tabular}{|c|c|c|}
\hline 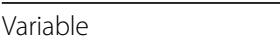 & Chi-square & $p$ value \\
\hline \multicolumn{3}{|l|}{ Histology } \\
\hline Adeno vs Non-adeno & 8.7 & $0.003^{*}$ \\
\hline \multicolumn{3}{|l|}{ Sex } \\
\hline Fvs M & 1.5 & 0.220 \\
\hline \multicolumn{3}{|l|}{ Age (year) } \\
\hline$\leq 54$ vs $55-74$ & 0.19 & 0.660 \\
\hline$\leq 54$ vs $\geq 75$ & 7.3 & $0.007^{*}$ \\
\hline $55-74$ vs $\geq 75$ & 6.41 & $0.010^{*}$ \\
\hline \multicolumn{3}{|l|}{ Pre-op PS } \\
\hline 0 vs 1 & 0.45 & 0.500 \\
\hline 0 vs 2 & 13.44 & $<0.001^{*}$ \\
\hline 1 vs 2 & 13.99 & $<0.001^{*}$ \\
\hline \multicolumn{3}{|l|}{ Pre-op palsy } \\
\hline 0 vs 1 & 0.027 & 0.870 \\
\hline \multicolumn{3}{|l|}{ Post-op palsy } \\
\hline 0 vs 1 & 1.95 & 0.160 \\
\hline 0 vs 2 & 6 & $0.010^{*}$ \\
\hline 1 vs 2 & 9.12 & $0.003^{*}$ \\
\hline \multicolumn{3}{|l|}{ BMI } \\
\hline 1 vs 2 & 0.02 & 0.878 \\
\hline 1 vs 3 & 1.07 & 0.301 \\
\hline 2 vs 3 & 0.97 & 0.324 \\
\hline \multicolumn{3}{|c|}{ Number of vertebra involved } \\
\hline$<3$ vs $\geq 3$ & 0.23 & 0.630 \\
\hline \multicolumn{3}{|l|}{ Other bone metastasis } \\
\hline Without vs with & 0.05 & 0.818 \\
\hline \multicolumn{3}{|l|}{ Visceral metastasis } \\
\hline Without vs with & 0.33 & 0.567 \\
\hline
\end{tabular}

*Significant at $p$-value $<0.05$

Adeno adenocarcinoma, Non-adeno non-adenocarcinoma, PS performance status, $B M I$ body mass index, BMI 1 underweight, 2 eutrophic, 3 overweight/obese 
Frankel A + B group and 8.0 months (95 \% CI: 5.529.89 months) in the Frankel $\mathrm{C}+\mathrm{D}$ group (Fig. $2 ; p=0.87$ ).

Log-rank test (Table 2) and pairwise comparisons of survival between subgroups (Table 3) showed that age $<75$ years, adenocarcinoma histology, higher preoperative performance status score, and higher postoperative palsy score were all significantly associated with longer survival. Sex, BMI, number of vertebra involved, other bone metastasis, visceral metastasis, and preoperative palsy score had no statistically significant association with survival.

Multivariate Cox proportional hazard regressions further showed that only higher preoperative performance status score had a statistically significant association with longer survival (Table 4).

\section{Discussion}

Tokuhashi et al. [2] stated that the average survival period was longer (10.4 \pm 13.6 months) in patients without neurologic deficits than in patients with complete palsy $(3.7 \pm$
3.9 months). Therefore, they included "spinal cord palsy" as a prognostic parameter in their study. Several authors have reported that patients with paralysis at presentation or posttreatment have a considerably shorter life expectancy than ambulatory patients [6-10]. Prasad and Schiff [11] reported that other than the nature of the primary tumor, the presence of paraparesis prior to surgery had the most detrimental effect on survival.

In 2001, Tomita et al. [3] developed a scoring system that does not use neurologic status as a prognostic factor for survival in patients with spinal metastases. The authors described that a long survival period can be possible with appropriate treatment, even in cases with paraplegia, and suggested that spinal cord decompression can improve paralytic conditions. Patients with paralysis tend to have shorter survival because of cancer progression and not due to the paralysis itself [3]. Spiegel et al. [12] reported that neurologic deficits did not significantly influence survival of melanoma patients. North et al. [13] observed that the preoperative ambulatory status

Table 4 Univariate and multivariate Cox proportional hazard regressions Model

\begin{tabular}{|c|c|c|c|c|}
\hline \multirow[b]{2}{*}{ Variable } & \multicolumn{2}{|l|}{ Univariate } & \multicolumn{2}{|l|}{ Multivariate } \\
\hline & Hazard ratio $(95 \%$ Cl) & $p$ value & Hazard ratio $(95 \% \mathrm{Cl})$ & $p$ value \\
\hline \multicolumn{5}{|l|}{ Sex } \\
\hline F (ref: M) & $0.61(0.33-1.14)$ & 0.120 & & \\
\hline \multicolumn{5}{|l|}{ Age (year) } \\
\hline 55-74 (ref: $\leq 54)$ & $1.16(0.6-2.25)$ & 0.659 & $0.78(0.37-1.64)$ & 0.512 \\
\hline$\geq 75$ (ref: $\leq 54)$ & $3.28(1.37-7.82)$ & $0.008^{*}$ & $1.22(0.37-4.05)$ & 0.748 \\
\hline \multicolumn{5}{|l|}{$\mathrm{BMI}\left(\mathrm{kg} / \mathrm{m}^{2}\right)$} \\
\hline Eutrophic (ref: underweight) & $1.03(0.39-2.68)$ & 0.958 & & \\
\hline Overweight (ref: underweight) & $0.72(0.25-2.05)$ & 0.538 & & \\
\hline \multicolumn{5}{|l|}{ Pre-op palsy } \\
\hline 1 (ref: 0) & $1.18(0.49-2.83)$ & 0.706 & $1.23(0.5-3.03)$ & 0.653 \\
\hline \multicolumn{5}{|l|}{ Post-op palsy } \\
\hline 1 (ref: 0) & $0.3(0.06-1.36)$ & 0.119 & & \\
\hline 2 (ref: 0) & $0.1(0.02-0.51)$ & $0.006^{*}$ & & \\
\hline \multicolumn{5}{|l|}{ PS score } \\
\hline 1 (ref: 0) & $0.43(0.18-1.03)$ & 0.059 & $0.52(0.16-1.74)$ & 0.289 \\
\hline 2 (ref: 0) & $0.09(0.03-0.26)$ & $<0.001^{*}$ & $0.14(0.03-0.54)$ & $0.004^{*}$ \\
\hline \multicolumn{5}{|l|}{ Histology } \\
\hline Adeno (ref: Non-adeno) & $0.38(0.2-0.71)$ & $0.003^{*}$ & $0.59(0.28-1.25)$ & 0.167 \\
\hline \multicolumn{5}{|l|}{ Number of vertebra involved } \\
\hline$\geq 3$ (ref: <3) & $0.7(0.39-1.25)$ & 0.228 & & \\
\hline \multicolumn{5}{|l|}{ Other bone metastasis } \\
\hline With (ref: without) & $0.83(0.46-1.49)$ & 0.531 & & \\
\hline \multicolumn{5}{|l|}{ Visceral metastasis } \\
\hline With (ref: without) & $1.08(0.52-2.23)$ & 0.837 & & \\
\hline
\end{tabular}


predicted the duration of postoperative ambulation but was only marginally associated with survival. Yamashita et al. [14] used the revised Tokuhashi scoring system to predict survival in patients with spinal metastases and found that Frankel grade was not significantly associated with survival. Kumar et al. [15] studied 87 patients with spinal metastases from nasopharyngeal cancer and found the modified Tokuhashi score was the best to predict prognosis; however, neurological status had no significant association with survival. Quraishi et al. [16] studied the effect of surgical timing on neurological outcome and survival in spinal metastases patients and found that earlier surgical treatment resulted in significantly better neurological outcomes. However, the timing of surgery did not influence survival.

Leithner et al. [17] compared 7 preoperative prognostic scoring systems for spinal metastases, including the Bauer [18], modified Bauer [19], Tokuhashi [2], revised Tokuhashi [1], Tomita [3], van der Linden [20], and Sioutos [21] scoring systems. In their analyses, primary tumor and visceral metastases were the only parameters significantly associated with survival. Their results did not show pretreatment neurological status as a prognostic factor; therefore, the authors did not consider paralysis as a predictive of survival [17, 22]. Wibmer et al. [23] evaluated the same preoperative scoring systems and found that primary tumor, status of visceral metastases, and systemic therapy were significantly associated with survival. Leithner et al. [17] and Wibmer et al. [23] further concluded that the Bauer and modified Bauer scoring systems are the most reliable systems for prediction of survival. The modified Bauer scoring system includes 4 positive prognostic factors: absence of visceral metastases, solitary skeletal metastasis, non-primary lung cancer, and primary tumor of the breast or kidney, lymphoma, or myeloma. It does not include preoperative neurological palsy as a parameter.

The parameters of the revised Tokuhashi scoring system include the patient's general condition, number of extraspinal bone metastases, number of metastases in the vertebral bodies, presence of metastases in the major internal organs, the primary site of the cancer, and the presence of palsy. The first 5 parameters are all associated with disease severity, but palsy score is not. In our study, the survivals of the Frankel $A+B$ and Frankel $C+D$ groups were not statistically different. One patient with preoperative Frankel B status improved to Frankel D postoperatively and survived for 16 months. One patient with preoperative Frankel B status improved to Frankel C postoperatively and survived for 36 months. Patients with preoperative Frankel B neurological status can still survive for a long duration.

These results may be because paralytic condition is not associated with disease severity, and paralytic condition can be improved with adequate spinal cord decompression. In a patient with multiple spine metastases, palsy might be
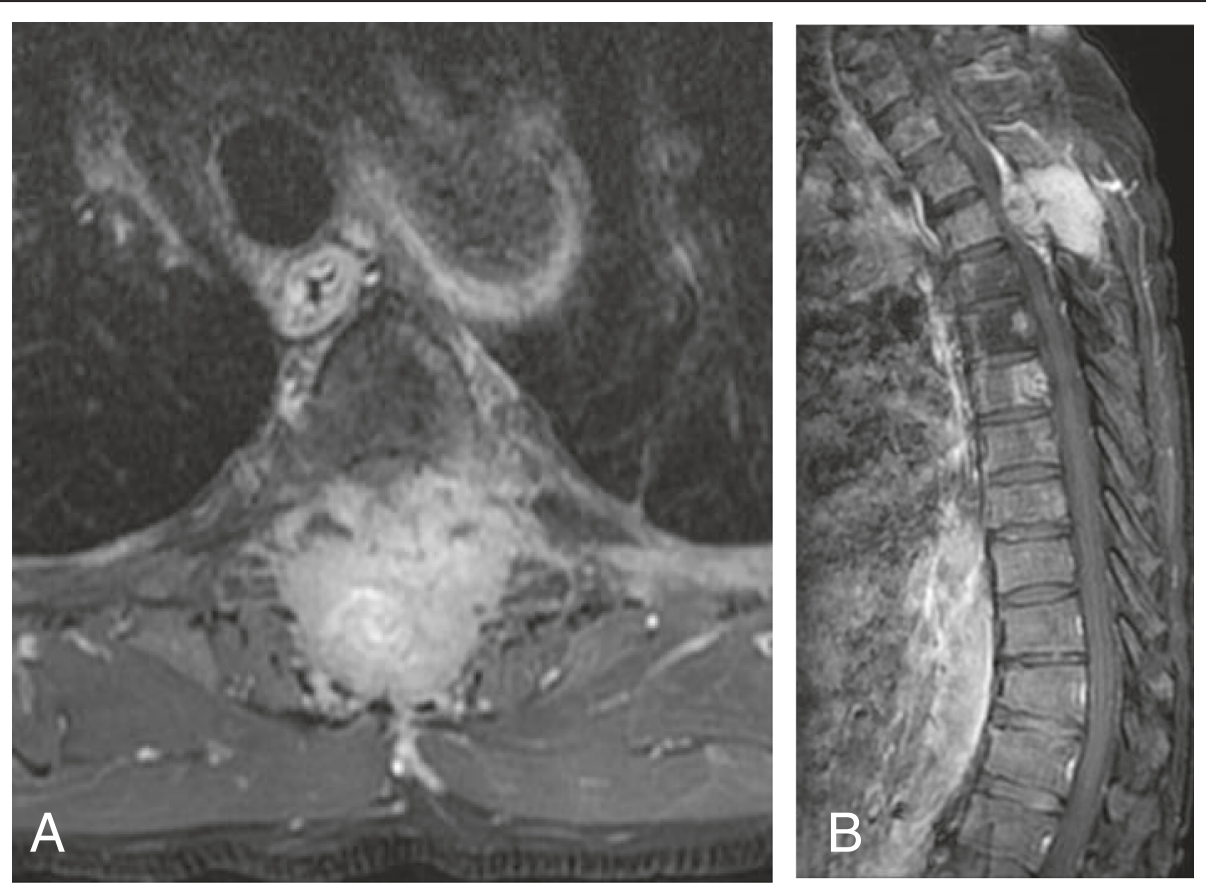

Fig. 3 A 69-year-old male lung cancer patient with T3, T6 metastases underwent spinal surgery; his preoperative palsy score was 0 (Frankel B). Axial (a) and sagittal (b) T1-weighted MR images with contrast enhancement demonstrate severe cord compression at T3. His postoperative palsy score was 1 (Frankel C), and he survived 289 days after spinal surgery 

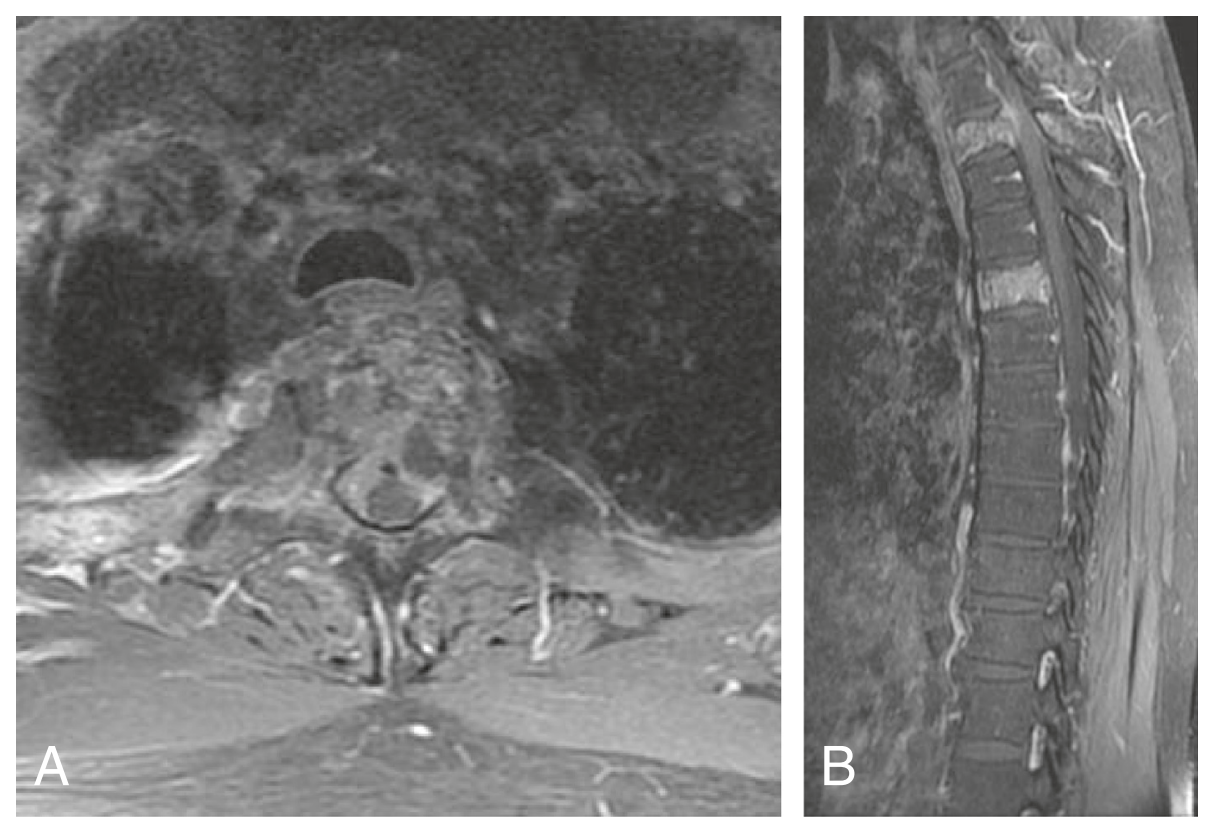

Fig. 4 A 51-year-old male lung cancer patient with T2, T5 metastases underwent spinal surgery; his preoperative palsy score was 1 (Frankel D). Axial (a) and sagittal (b) T1-weighted MR images with contrast enhancement demonstrate cord compression at T2. His postoperative palsy score was 1 (Frankel D), and he survived 274 days after spinal surgery

absent. However, palsy might be noted in a patient with only 1 vertebral metastasis. A patient with multiple spinal metastases generally has higher disease severity than a patient with a single vertebral metastasis. Also, the number of vertebrae involved and the pattern of spinal cord compression might be the same in patients with different palsy score (Figs. 3 and 4). Deterioration of neurological status might occur in 1 week, and the survival time should not differ too much in such situation. After adequate surgical decompression and stabilization, palsy should be reversed in all patients except those with a neurological status of Frankel A, or those with a poor overall medical status [24]. Thus, palsy should not be a major prognostic factor in lung cancer patients with spinal metastasis who underwent spinal surgery. Patients with paralysis tend to have shorter survival because of cancer progression, not due to the paralysis itself [3]. The duration of survival largely depends on the disease severity and the ability of other modalities (such as chemotherapy, targeted therapy, or radiotherapy) to control the tumor [25-28].

This study has some limitations that should be considered. First, as a retrospective study from a single center, several potential biases may exist, including referral bias and patient characteristics. Second, the sample size was small. Third, we did not include all parameters in the analyses. However, this is the first study that focused only on non-small-cell lung cancer patients with spinal metastases who underwent spinal surgery. The result of this study should be valuable in the decision of treatment of nonsmall-cell lung cancer patients with spinal metastases.

\section{Conclusions}

Preoperative palsy score had no statistically significant association with survival in non-small-cell lung cancer patients with spinal metastases who underwent spinal surgery.

\section{Abbreviations}

BMI: body mass index; Cl: confidence interval; CT: computed tomography; MRI: magnetic resonance imaging; PTA: posterolateral transpedicular approach.

\section{Competing interests}

The authors declare that they have no competing interests.

\section{Authors' contributions}

YJC collected the data, performed the statistical analysis, and wrote the manuscript. HTC participated in the design of the study and the statistical analysis. $\mathrm{HCH}$ participated in its design and coordination and helped to draft the manuscript. All authors read and approved the final manuscript.

\section{Author details}

'Department of Orthopedic Surgery, China Medical University Hospital Taichung, Taiwan, No. 2, Yuh-Der Road, Taichung 404, Taiwan. ${ }^{2}$ Department of Orthopedic Surgery, School of Medicine, China Medical University, Taichung, Taiwan. ${ }^{3}$ Department of Public Health and Department of Health Services Administration, China Medical University, Taiwan, No. 91, Hsueh-Shuh Road, Taichung 404, Taiwan.

Received: 1 February 2015 Accepted: 7 September 2015

Published online: 17 September 2015

\section{References}

1. Tokuhashi Y, Matsuzaki H, Oda H, Oshima M, Ryu J. A revised scoring system for preoperative evaluation of metastatic spine tumor prognosis. Spine (Phila Pa 1976). 2005;30:2186-91.

2. Tokuhashi Y, Matsuzaki H, Toriyama S, Kawano H, Ohsaka S. Scoring system for the preoperative evaluation of metastatic spine tumor prognosis. Spine (Phila Pa 1976). 1990;15:1110-3. 
3. Tomita K, Kawahara N, Kobayashi T, Yoshida A, Murakami H, Akamaru T. Surgical strategy for spinal metastases. Spine (Phila Pa 1976). 2001;26:298-306.

4. Frankel HL, Hancock DO, Hyslop G, Melzak J, Michaelis LS, Ungar GH, et al. The value of postural reduction in the initial management of closed injuries of the spine with paraplegia and tetraplegia. I. Paraplegia. 1969;7:179-92.

5. Klein JP, Moeschberger M. Survival analysis: techniques for censored and truncated data. New York: Springer; 2003.

6. Hessler C, Vettorazzi E, Madert J, Bokemeyer C, Panse J. Actual and predicted survival time of patients with spinal metastases of lung cancer: evaluation of the robustness of the Tokuhashi score. Spine (Phila Pa 1976). 2011;36:983-9.

7. Leviov M, Dale J, Stein M, Ben-Shahar M, Ben-Arush M, Milstein D, et al. The management of metastatic spinal cord compression: a radiotherapeutic success ceiling. Int J Radiat Oncol Biol Phys. 1993;27:231-4.

8. Maranzano E, Latini P. Effectiveness of radiation therapy without surgery in metastatic spinal cord compression: final results from a prospective trial. Int J Radiat Oncol Biol Phys. 1995;32:959-67.

9. Sundaresan N, Galicich JH, Lane JM, Bains MS, McCormack P. Treatment of neoplastic epidural cord compression by vertebral body resection and stabilization. J Neurosurg. 1985;63:676-84.

10. Zelefsky MJ, Scher HI, Krol G, Portenoy RK, Leibel SA, Fuks ZY. Spinal epidural tumor in patients with prostate cancer. Clinical and radiographic predictors of response to radiation therapy. Cancer. 1992;70:2319-25.

11. Prasad D, Schiff D. Malignant spinal-cord compression. Lancet Oncol. 2005;6:15-24.

12. Spiegel DA, Sampson JH, Richardson WJ, Friedman AH, Rossitch E, Hardaker Jr WT, et al. Metastatic melanoma to the spine. Demographics, risk factors, and prognosis in 114 patients. Spine (Phila Pa 1976). 1995;20:2141-6.

13. North RB, LaRocca VR, Schwartz J, North CA, Zahurak M, Davis RF, et al. Surgical management of spinal metastases: analysis of prognostic factors during a 10-year experience. J Neurosurg Spine. 2005;2:564-73.

14. Yamashita $T$, Siemionow KB, Mroz TE, Podichetty $V$, Lieberman $\mathbb{H}$. A prospective analysis of prognostic factors in patients with spinal metastases: use of the revised tokuhashi score. Spine (Phila Pa 1976). 2011;36:910-7.

15. Kumar N, Tan JJ, Zaw AS, Lim JL, Wai KL, Malhotra R, et al. Evaluation of scoring systems and prognostic factors in patients with spinal metastases from nasopharyngeal carcinoma. Spine J. 2014;14:2946-53.

16. Quraishi NA, Rajagopal TS, Manoharan SR, Elsayed S, Edwards KL, Boszczyk BM. Effect of timing of surgery on neurological outcome and survival in metastatic spinal cord compression. Eur Spine J. 2013;22:1383-8.

17. Leithner A, Radl R, Gruber G, Hochegger M, Leithner K, Welkerling H, et al. Predictive value of seven preoperative prognostic scoring systems for spinal metastases. Eur Spine J. 2008;17:1488-95.

18. Bauer HC, Wedin R. Survival after surgery for spinal and extremity metastases. Prognostication in 241 patients. Acta Orthop Scand. 1995:66:143-6.

19. Bauer H, Tomita K, Kawahara N, Abdel-Wanis ME, Murakami H. Surgical strategy for spinal metastases. Spine (Phila Pa 1976). 2002;27:1124-6.

20. van der Linden YM, Dijkstra SP, Vonk EJ, Marijnen CA, Leer JW. Prediction of survival in patients with metastases in the spinal column: results based on a randomized trial of radiotherapy. Cancer. 2005;103:320-8.

21. Sioutos PJ, Arbit E, Meshulam CF, Galicich JH. Spinal metastases from solid tumors. Analysis of factors affecting survival. Cancer. 1995;76:1453-9.

22. Dardic M, Wibmer C, Berghold A, Stadlmueller L, Froehlich EV, Leithner A. Evaluation of prognostic scoring systems for spinal metastases in 196 patients treated during 2005-2010. Eur Spine J. 2014. Epub 2014/08/02.

23. Wibmer C, Leithner A, Hofmann G, Clar H, Kapitan M, Berghold A, et al. Survival analysis of 254 patients after manifestation of spinal metastases: evaluation of seven preoperative scoring systems. Spine (Phila Pa 1976). 2011;36:1977-86

24. Chen YJ, Chang GC, Chen HT, Yang TY, Kuo BI, Hsu HC, et al. Surgical results of metastatic spinal cord compression secondary to non-small cell lung cancer. Spine (Phila Pa 1976). 2007;32:E413-8.

25. Bridwell KH, Jenny AB, Saul T, Rich KM, Grubb RL. Posterior segmental spinal instrumentation (PSSI) with posterolateral decompression and debulking for metastatic thoracic and lumbar spine disease. Limitations of the technique. Spine (Phila Pa 1976). 1988;13:1383-94.

26. Cufer T, Knez L. Update on systemic therapy of advanced non-small-cell lung cancer. Expert Rev Anticancer Ther. 2014;14:1189-203.
27. Cufer T, Ovcaricek T, O'Brien ME. Systemic therapy of advanced non-small cell lung cancer: major-developments of the last 5-years. Eur J Cancer. 2013:49:1216-25.

28. Harshman LC, Drake CG, Wargo JA, Sharma P, Bhardwaj N. Cancer immunotherapy highlights from the 2014 ASCO meeting. Cancer Immunol Res. 2014;2:714-9.

\section{Submit your next manuscript to BioMed Central and take full advantage of:}

- Convenient online submission

- Thorough peer review

- No space constraints or color figure charges

- Immediate publication on acceptance

- Inclusion in PubMed, CAS, Scopus and Google Scholar

- Research which is freely available for redistribution 